\title{
The 2020 metabolomics publication awards
}

\section{Royston Goodacre ${ }^{1}$}

๑) Springer Science+Business Media, LLC, part of Springer Nature 2020
Metabolomics is very proud to publish papers and reviews that are very well received by the community. Therefore, in order to appreciate the excellent research published in Metabolomics the following prizes are awarded to the most downloaded original articles and reviews published in the previous year:

- Best Paper Award-for the Original Article with the highest total number of downloads during the previous year. The first author of the winning paper receives a complimentary ebook from Springer (value 200€), a front cover image in the Metabolomics journal, and the paper will be made freely available for 30 days.

The runner-up paper will also be made freely available for 30 days.

- Best Review Award-for the Review Article with the highest total number of downloads during the previous year. The first author of the winning paper receives complimentary e-books from Springer (value 200€), a front cover image in the Metabolomics journal, and the paper will be made freely available for 30 days.

The runner-up review will also be made freely available for 30 days.

In order for a paper to be eligible for these awards it must be either a primary research paper (which may include best practice or standards articles, as well as letters and short communications) or a review article (which includes white papers) that was published in its final form in 2019. All awards will be based on popularity via downloads.

Congratulations to the following 2020 winners!!!

Royston Goodacre

roy.goodacre@liverpool.ac.uk

1 Department of Biochemistry, Institute of Integrative Biology, University of Liverpool, Biosciences Building, Crown Street, Liverpool L69 7ZB, UK

\section{Best Paper Award published in 2019} Winner-

- King, M., Mullin, L.G., Wilson, I.D., Coen, M., Rainville, P.D., Plumb, R.S., Gethings, L.A., Maker, G. \& Trengove, R. (2019) Development of a rapid profiling method for the analysis of polar analytes in urine using HILIC-MS and ion mobility enabled HILIC-MS. Metabolomics 15: 17. https://doi.org/10.1007/S11306-0191474-9.

\section{Runner up -}

- Mora-Ortiz, M., Ramos, P.N., Oregioni, A. \& Claus, S.P. (2019) NMR metabolomics identifies over 60 biomarkers associated with Type II Diabetes impairment in $d b / d b$ mice. Metabolomics 15: 89. https://doi.org/10.1007/ S11306-019-1548-8.

\section{Best Review Award published in 2019 Winner -}

- Mendez, K.M., Pritchard, L., Reinke, S.N. \& Broadhurst, D.I. (2019) Toward collaborative open data science in metabolomics using Jupyter Notebooks and cloud computing. Metabolomics 15: 125. https://doi.org/10.1007/ S11306-019-1588-0.

\section{Runner up -}

- Rangel-Huerta, O.D., Pastor-Villaescusa, B. \& Gil, A. (2019) Are we close to defining a metabolomic signature of human obesity? A systematic review of metabolomics studies. Metabolomics 15: 93. https://doi.org/10.1007/ S11306-019-1553-Y.

Publisher's Note Springer Nature remains neutral with regard to jurisdictional claims in published maps and institutional affiliations. 